\title{
Neuro imaging
}

\section{Presentation}

A 50 year-old gentleman of otherwise excellent health presents with recent onset of left upper limb weakness and left facial nerve palsy. These are selected MR images.

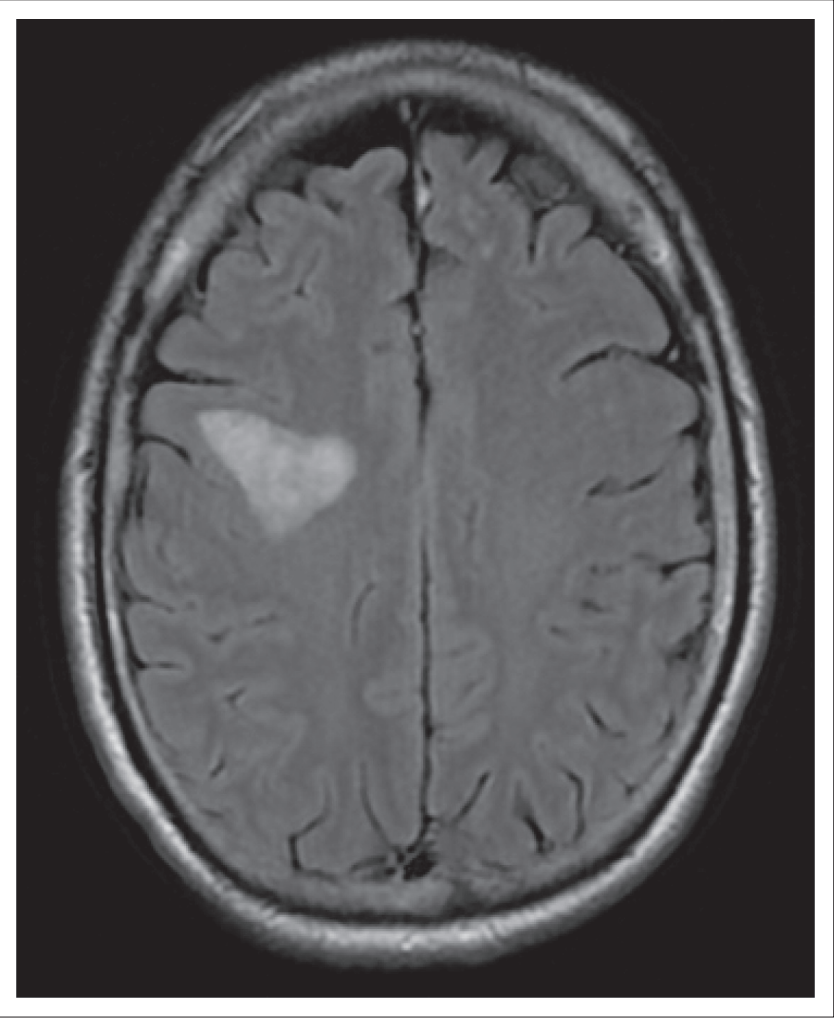

FIGURE 1: Axial FLAIR MR image.

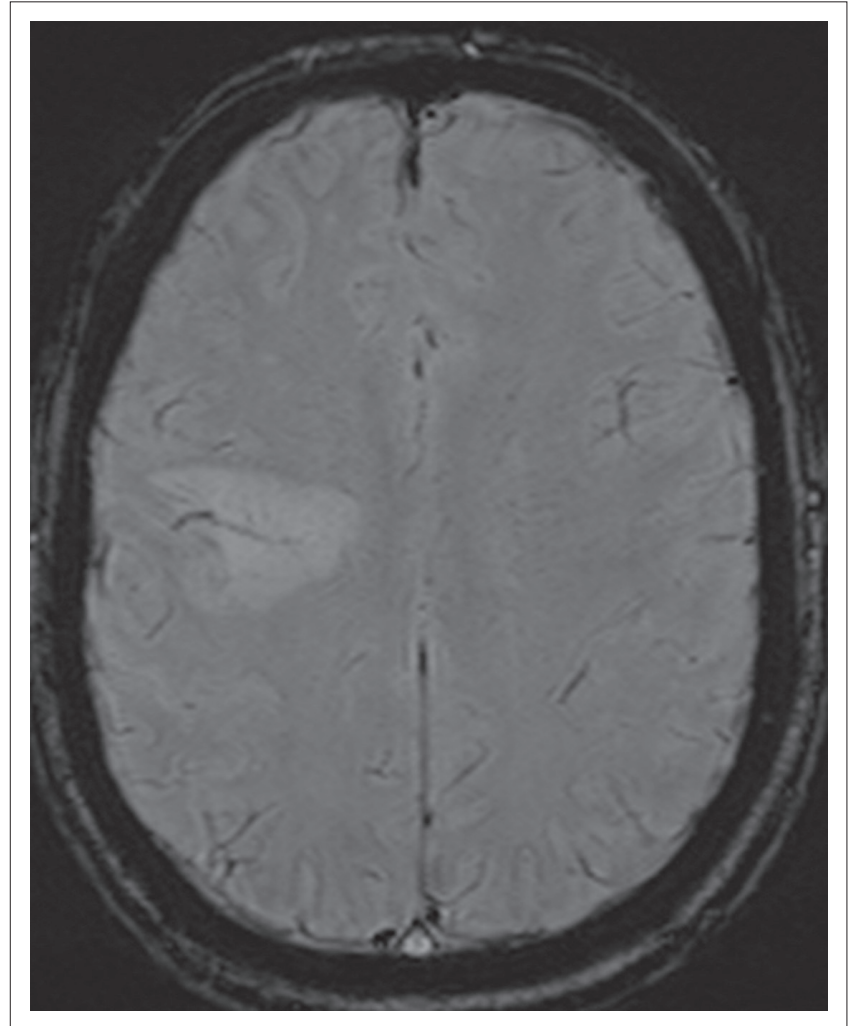

FIGURE 2: Axial SWI MR image.

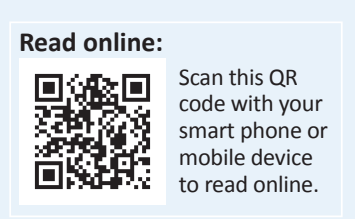

Authors: Shalendra K. Misser ${ }^{1}$, Thami Z. Mngoma

Affiliation: ${ }^{1}$ Lake Smit and Partners Inc, Durban, South Africa

Correspondence to: Shalendra Misser

Email: misser@lakesmit.co.za

Postal address: Private Bag X08, Overport 4067, Durban, South Africa

How to cite this article: Misser, SK, Mngoma, TZ. Neuro imaging. S Afr J Rad. 2015;19(1); Art. \#815, 3 pages. http://dx.doi. org/10.4102/sajr.v19i1.815

Copyright: (c) 2015. The Authors. Licensee: AOSIS OpenJournals. This work is licensed under the Creative Commons Attribution License. 


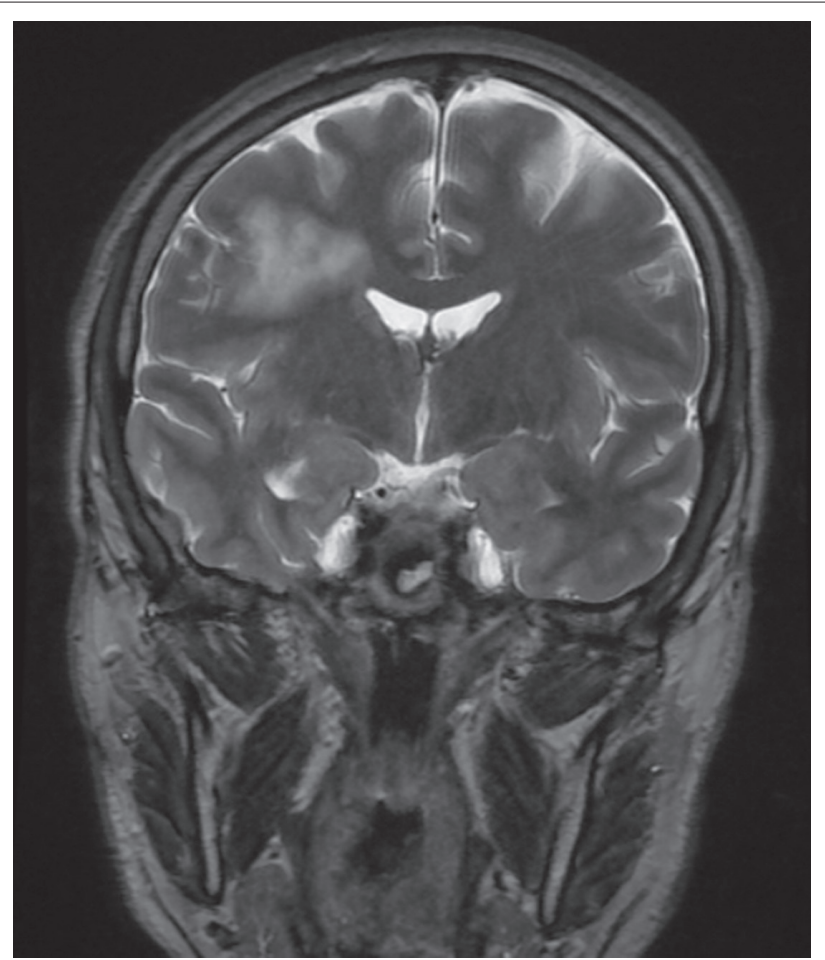

FIGURE 3: Coronal T2-weighted MR image.

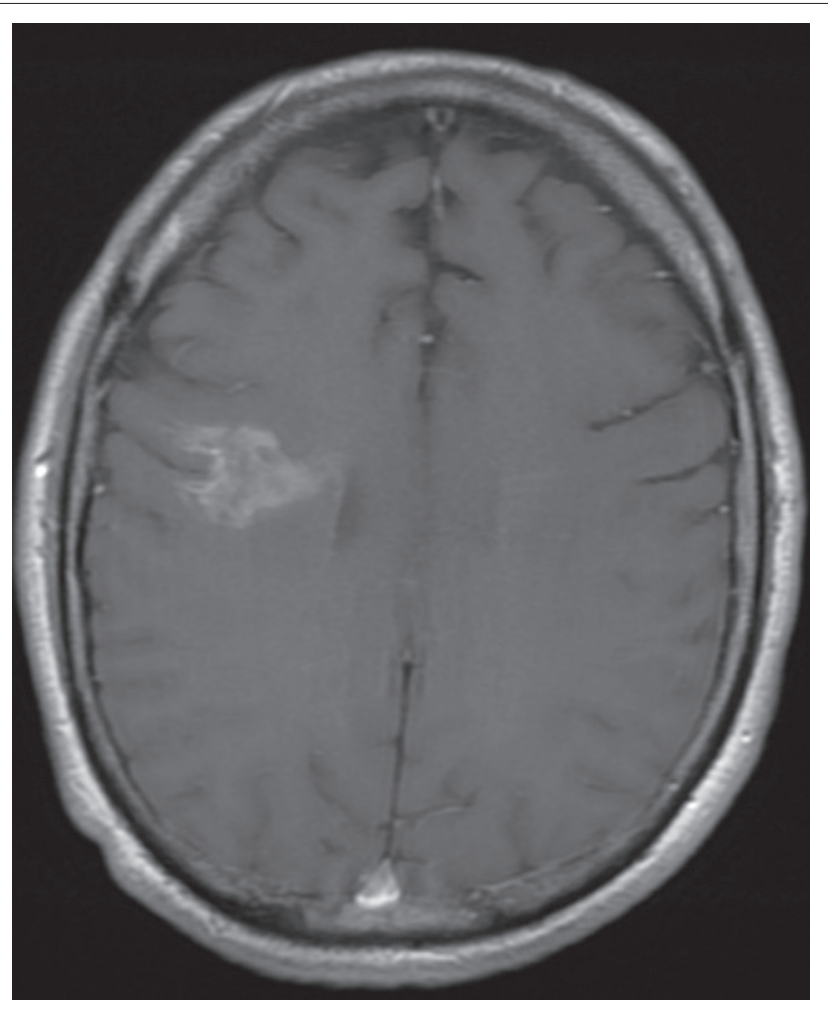

FIGURE 5: Axial post contrast T1-weighted MR image

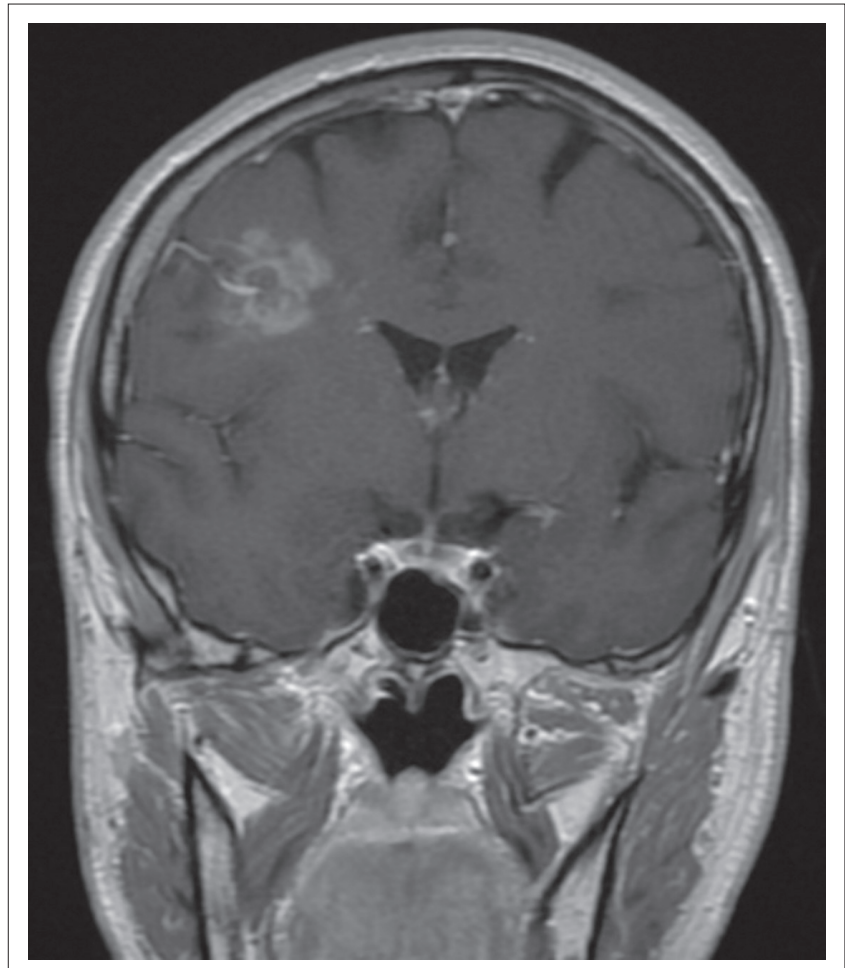

FIGURE 4: Coronal post contrast T1-weighted MR image.

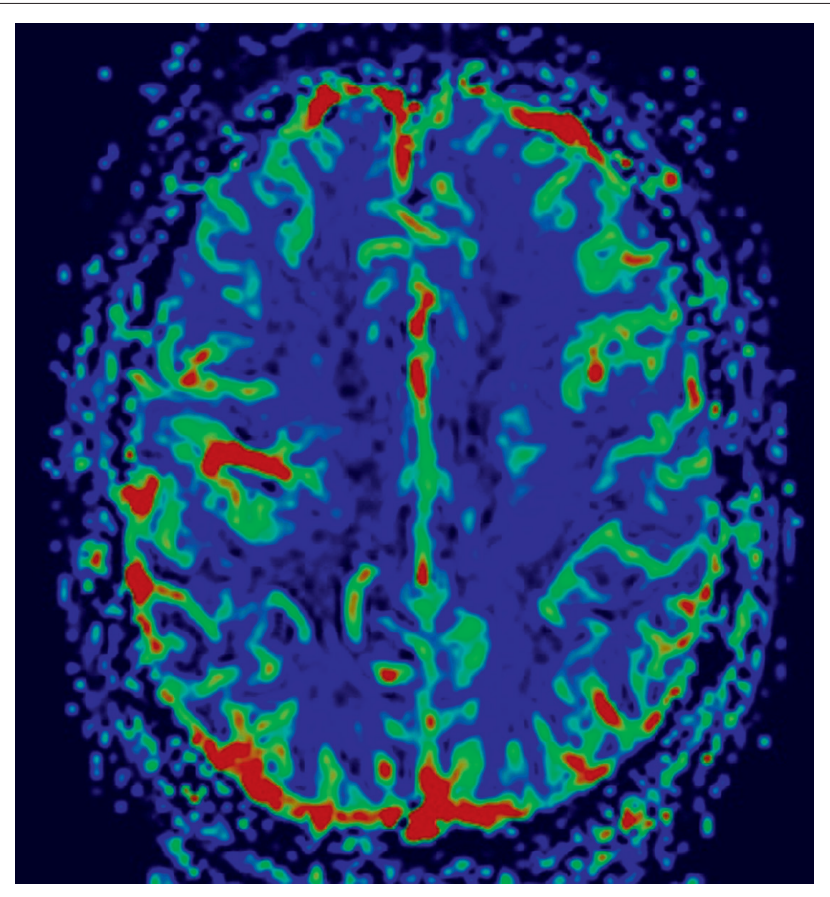

FIGURE 6: Axial rCBV MR Perfusion image. 


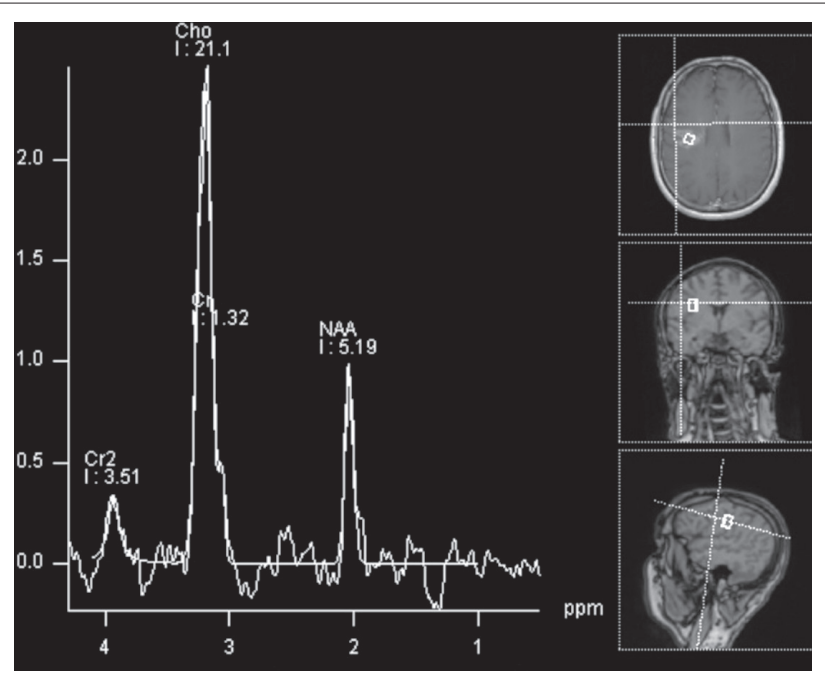

FIGURE 7: MR Spectroscopy image obtained at TE $135 \mathrm{~ms}$.
Describe the relevant imaging findings and formulate the most appropriate clinical diagnosis. Please submit your response to misser@lakesmit.co.za not later than 30 September 2015. The winning respondent will receive a R1000 award from the RSSA. A detailed diagnosis and discussion will be presented in the next issue of the SAJR. 